\title{
Mitral regurgitation recovery and atrial reverse remodeling following pulmonary vein isolation procedure in patients with atrial fibrillation: a proof of concept cardiac MRI study
}

\author{
Sahadev T Reddy*, William Belden, Mark Doyle, Diane A Vido, June Yamrozik, Ronald B Williams,
} Robert W Biederman

From 15th Annual SCMR Scientific Sessions

Orlando, FL, USA. 2-5 February 2012

\section{Summary}

Atrial reverse remodeling triggered by favorable pulmonary vein isolation for atrial fibrillation results in regression of mitral regurgitation.

\section{Background}

Atrial fibrillation (AF) is a chronic and progressive disease, and if uncontrolled results in permanent remodeling of the myocardium. Reverse remodeling of the left atrium (LA) after the successful pulmonary vein isolation (PVI) in recurrent/chronic AF may occur, however, mitral regurgitation (MR) recovery after the successful PVI has not been demonstrated but would be an important factor in PVI durability.

\section{Objective}

Retrospectively analyze the effectiveness of pulmonary vein isolation (PVI) procedure in patients with AF for evidence of atrial reverse remodeling and recovery of MR via CMR.

\section{Methods}

Prior to PVI, patients underwent a clinically indicated CMRI, post-PVI ( $6 \pm 1$ months) patients underwent a follow up MRI, and were classified into 2 groups: responders (R) to PVI, non responders (NR) to PVI as assessed by cessation of $\mathrm{AF}$ at the end of 3 month blanking period. Further, CMR was used to evaluate the severity of MR (0 to 4+) and to relate changes in MR to LA, LAA volumes as well as mitral apparatus (mitral annulus,

Allegheny General Hospital, Pittsburgh, USA tenting area, tenting height and tenting angle). For continuous variables, group differences were assessed by unpaired or paired two-sample $t$ tests or their non-parametric equivalents. We used chi-square tests for evaluating categorical variables.

\section{Results}

Of the 94 patients with AF who underwent PVI, 76 (81\%) were classified as R and 18 (19\%) were classified as NR. Mean age, mean BSA and antiarrhythmic therapies were similar between the groups. MR pre vs. post in the R group significantly improved (Mean 0.78, Median 1.0 vs. Mean 0.51, Median 0, P 0.01) and was matched by favorable mitral geometry reverse remodeling [annulus $(34.5 \pm 3.9 \mathrm{~mm}$ vs. $32.6 \pm 3.9 \mathrm{~mm}, \mathrm{p}$ $<0.001)$, tenting area $(169.7 \pm 55.9 \mathrm{~mm} 2$ vs. $139.0 \pm 40.6$ $\mathrm{mm} 2, \mathrm{p}<0.001)$, and tenting height $(8.0 \pm 2.0 \mathrm{~mm}$ vs. $7.2 \pm 1.8 \mathrm{~mm}, \mathrm{p}<0.001)$, tenting angle $\left(128^{\circ} \pm 11^{\circ}\right.$ vs. $\left.\left.130^{\circ} \pm 10^{\circ}\right)\right]$. However, in the NR group MR failed to improve (Mean 1.06 Med 1.0 vs. Mean 0.67 Med 0, p NS), and paralleled failure of mitral geometry reverse remodeling [annulus $(33.1 \pm 4.0 \mathrm{~mm}$ vs. $32.9 \pm 3.6 \mathrm{~mm}$, p NS), tenting area $(154.0 \pm 42.0 \mathrm{~mm} 2$ vs. $143.9 \pm 45.4$ $\mathrm{mm} 2$, p NS), tenting height $(6.9 \pm 1.9 \mathrm{~mm}$ vs. $7.0 \pm 1.8$, p NS), tenting angle $\left(131^{\circ} \pm 11\right.$ vs. $\left.130^{\circ} \pm 10^{\circ}\right)$ ]. Likewise, LVESD, LVEF, LA volume, and RA volumes pre to post PVI favorably improved in the R group but not in NR (table 1).

\section{Conclusions}

Long-term success rate in AF patients following PVI remains suboptimal. In those with successful and

(c) 2012 Reddy et al; licensee BioMed Central Ltd. This is an open access article distributed under the terms of the Creative Commons 
Table 1

\begin{tabular}{|c|c|c|c|c|c|c|}
\hline \multirow[t]{2}{*}{ Cardiac MRI parameters } & \multicolumn{2}{|c|}{ Responders to PVI $(n=76)$} & \multirow[t]{2}{*}{$P$ Value } & \multicolumn{2}{|c|}{ Non-responders to PVI $(n=18)$} & \multirow[t]{2}{*}{ P Value } \\
\hline & PRE PVI & POST PVI & & PRE PVI & POST PVI & \\
\hline LAA VOLUME (ml) & $3.3 \pm 1.7$ & $3.1 \pm 1.8$ & NS & $3.0 \pm 2.0$ & $4.0 \pm 1.8$ & $<0.05$ \\
\hline LAA Os (mm) & $19 \pm 4$ & $18 \pm 4$ & NS & $18 \pm 4$ & $20 \pm 4$ & $<0.05$ \\
\hline LA volume Index (ml/m/2) & $103 \pm 32$ & $89 \pm 29$ & $<0.01$ & $95 \pm 29$ & $83 \pm 37$ & NS \\
\hline LVEF \% & $57 \pm 10$ & $60 \pm 6$ & $<0.001$ & $59 \pm 9$ & $60 \pm 8$ & NS \\
\hline RA Volume Index $(\mathrm{ml} / \mathrm{m} / 2)$ & $67 \pm 22$ & $59 \pm 20$ & $<0.001$ & $45 \pm 19$ & $54 \pm 18$ & NS \\
\hline MR Severity (0 to $4+$ ) & 0.78 & .51 & $<0.05$ & 1.06 & 0.67 & NS \\
\hline $\operatorname{LVEDD}(\mathrm{mm})$ & $52 \pm 5$ & $52 \pm 5$ & NS & $50 \pm 6$ & $52 \pm 6$ & NS \\
\hline LVESD (mm) & $35 \pm 6$ & $33 \pm 6$ & $<0.01$ & $35 \pm 6$ & $35 \pm 6$ & NS \\
\hline
\end{tabular}

durable maintenance of NSR, ventricular and atrial (LA and LAA) reverse remodeling demonstrated by 3D CMR occurs that is matched with marked improvements in mitral regurgitation and mitral apparatus likely begetting continued maintenance of NSR.

\section{Funding}

Internal.

Published: 1 February 2012

doi:10.1186/1532-429X-14-S1-P210

Cite this article as: Reddy et al:: Mitral regurgitation recovery and atrial reverse remodeling following pulmonary vein isolation procedure in patients with atrial fibrillation: a proof of concept cardiac MRI study. Journal of Cardiovascular Magnetic Resonance 2012 14(Suppl 1):P210.

Submit your next manuscript to BioMed Central and take full advantage of:

- Convenient online submission

- Thorough peer review

- No space constraints or color figure charges

- Immediate publication on acceptance

- Inclusion in PubMed, CAS, Scopus and Google Scholar

- Research which is freely available for redistribution

Submit your manuscript at www.biomedcentral.com/submit 